
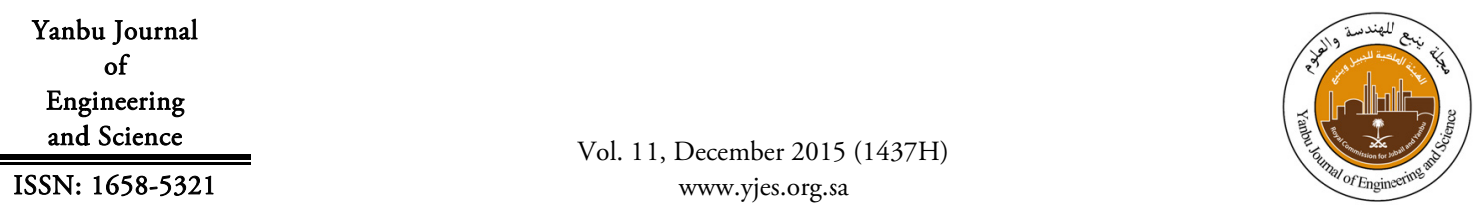

\title{
THEORETICAL APPROACH TO STUDY SELF-ORGANIZING PROPERTIES OF A NEMATIC LIQUID CRYSTAL WITH CARBON NANOSOLID MODELS
}

\author{
Mehdi Salih Shihab \\ Department of Chemistry, College of Science, Alnahrain University, Iraq \\ E-mail:mehdi_shihab@yahoo.com
}

\begin{abstract}
A theoretical study on stable geometries of a nematic liquid crystal (LC) molecule (4methoxybenzylidene-4'-n-butylaniline (MBBA)) assembled on the carbon nanosolid (CNS) surface models (graphite sheet and carbon nanotube (CNT): zigzag, armchair) has been carried out by using semi-empirical molecular quantum calculations within the parameterized model number 3 method as implemented in the Hyperchem package. The interaction of $\pi, \pi$-stacking between the MBBA molecules present on the CNS wall led to the formation of local short-range orientational order due to the LC-CNS binding energy. The binding energy of the LC molecule on the CNS surface was the typical van der Waals interaction. The results of this study showed that the assembly of LC-zigzag CNT system was a preferable model compared with the other available models.
\end{abstract}

\section{Keywords: 4-Methoxybenzylidene-4'-n-Butylaniline (MBBA), Carbon Nanosalid, Binding Energy, $\pi, \pi$-Stacking.}

\section{INTRODUCTION}

Biochemistry, supramolecular chemistry, and materials science deal with various types of non-covalent interactions that play an important role in various chemical researches as organic chemistry, molecular biological science, semiconductor physics science, micro-fabrication, and surface science $[1,2]$. These interactions can be manifested in various non-covalent forces acting between the carbon nanosolid (CNS) and molecular, ionic or macromolecular species constituting the CNS environment [3].

The $\pi, \pi$ - interactions are the weak noncovalent interactions commonly observed in the self-assembled systems. These interactions between $\pi$-units are often used to promote and stabilize molecular packing [4]. The carbon nanotubes (CNT) dispersed in liquid crystalline media [5,6] have attained great distribution.

Researchers have concentrated on the dispersion of CNT in liquid crystals (LCs) for lower threshold voltage, faster switching time, and better optical responses $[7,8]$.

Quantum chemical calculations could give useful information about the electron configuration of material components to investigate the relationship between the molecular structure and environmental media. Theoretical calculations predict that the strong anchoring energy due to $\pi, \pi$-electron stacking between LC-CNT molecules is associated with the CNT alignment mechanism in the nematic state $[9,10]$.

Other theoretical studies [11] considered the ordering of simple anisotropic particles in an LC environment. Some researchers used the nematic director field to study the equilibrium orientation of an elongated 
particle immersed in a nematic LC phase [12]. Andrienko [13] used molecular dynamics simulations to examine the defects in the structures and torque around a spherocylinder and a rod of infinite length placed in a nematic phase. In a previous paper [14], we presented a theoretical approach using semi-empirical quantum calculation for predicting stable geometries of N-4'Methoxy- benzylidine-4-n- butylaniline (MBBA) molecules assembled on single CNT wall (zigzag type).

It is well known from the calculated data [14] that the process of MBBA adsorption on CNT occurs by $\pi-\pi$ stacking between CNT and $\mathrm{LC}$, resulting in almost flat-laying $\mathrm{LC}$ molecules. Therefore, there is a necessity for demonstrating the specific relationships by comparing and analyzing the nature of molecular ordering interactions between a nematic liquid crystal (MBBA) and different kinds of CNS (graphite sheet and CNT: zigzag, armchair).

\section{METHODOLOGY}

The semi-empirical molecular quantum calculations included PM3 (parameterized model number 3) method [15] and molecular mechanics within the $\mathrm{MM}+$ level, as implemented in Hyperchem package version 7.52 [Hypercube Inc., Gainsville FL., 2005]. These calculations were used to find the geometry optimization of the more stable molecular structures and calculate the total energy. No frozen core approximation was used throughout the calculations. All calculations were carried out in the gas phase at $25^{\circ} \mathrm{C}$. The binding (or adsorption) energy $\left(E_{\mathrm{ad}}\right)$ of the LC molecule on the CNS wall is defined as:

$E_{\text {ad }}=E_{\mathrm{t}}(\mathrm{CNS}-\mathrm{LC})-E_{\mathrm{t}}(\mathrm{CNS})-E_{\mathrm{t}}(\mathrm{LC})$

where, $E_{\mathrm{t}}$ is the calculated total energy of a given system.
LC molecule (MBBA) is considered as a typical model for calculations. In addition to one azomethane fragment as a mesogenic group, the LC molecule has two hexagonal head parts with methoxy fragment and an alkyl chain tail part [14]. The head part contains a polar terminal group or polar lateral group, and it mainly determines the dielectric anisotropy $(\Delta \varepsilon)$ of the superfluorinated LC molecule [9].

The interaction between the CNS and LC molecule has been fully incorporated in the model calculation.

We considered the model systems of CNS with short length compared with the experimentally used one but at least longer than the LC length $(1600 \mathrm{pm})$ :

- Zigzag CNT: (10, 0), CNT length of nine layers with $2000 \mathrm{pm}$ length along the tube axis and $800 \mathrm{pm}$ diameter, opened nanotube, hydrogen-terminated carbon-nanotube (13), as shown in scheme 1 .

- Armchair CNT: $(5,5)$, CNT length of nine layers with $2300 \mathrm{pm}$ length along the tube axis and $700 \mathrm{pm}$ diameter, opened nanotube, hydrogen-terminated carbon-nanotube, see scheme 1 .
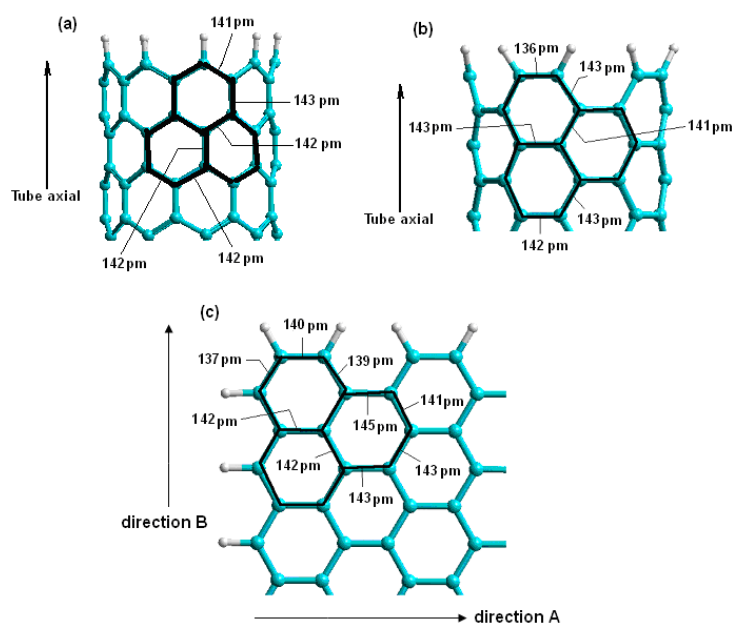

Scheme 1. Part of hydrogen terminated opened carbon nanosolid: (a) zigzag carbon nanotubes (CNT) $(10,0)$, (b) armchair CNT, and (c) graphite sheet. Showing the length of some of the C-C bonds. 
- Graphite sheet: length and width of nine layers with $\approx 2000 \mathrm{pm}$ length along the direction $A$ and $\approx 2300$ pm length along the direction $\mathrm{B}$, opened nanotube, hydrogenterminated, as shown in scheme 1 .

\section{RESULTS AND DISCUSSION}

3.1. THE STABLE GEOMETRY OF THE MBBA MOLECULE

According to a previous study [14], the total energy of MBBA molecule structure was determined using PM3 method, and its most stable geometry is shown in Figure 1. The LC molecule contains $\mathrm{N}, \mathrm{O}$, and $\mathrm{C}$ atoms, with an overall negative charge for the whole structure. This was confirmed from the Mulliken charge population within the PM3 method [16]. This difference in charge transfer leads to the creation of a valuable dielectric constant. The conformational structure of MBBA molecule in the mesogenic model (we suggest head and tail terms) is shown in Figure 1.

Figure 1 depicts the flat conformation of LC (related to imine group with two rings) to be the most stable geometry. The flat conformation makes dihedral angles $\left(\mathrm{C}_{1}-\mathrm{N}_{2}-\right.$ $\mathrm{C}_{3}-\mathrm{C}_{4}$ and $\mathrm{N}_{2}-\mathrm{C}_{1}-\mathrm{C}_{5}-\mathrm{C}_{6}$ ) that are equal to zero (related to imine group with two rings). Thus, it has minimum angular and torsional strains. This flat structure geometry was used in the rest of our calculations to study the interaction between the CNS and LC molecule.

\subsection{INTERACTION APPROACH BETWEEN THE MBBA MOLECULE AND CNS SURFACE.}

The stable geometry of the CNS molecules (graphite sheet and CNT: zigzag, armchair) was determined using the semi-empirical molecular quantum calculations within the PM3 method [14]. Optimization geometries of opened CNS molecules were hydrogenterminated. In addition to representing the

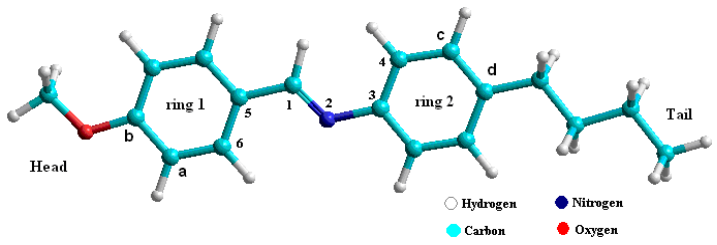

Fig.1. Conformational structure of the MBBA molecule that was calculated using semi-empirical molecular quantum calculations within the PM3 method as implemented in the Hyperchem package. opened CNT, the termination of dangling bonds provided less strain to the carbon atoms near the edge, making them ideal structures. It also enhanced the computational speed by using $\mathrm{MM}+$ method for primary optimization, followed by semi-empirical PM3 method as the final optimization step.

With some modifications to a previous study [14], we defined the assembly of the MBBA molecules on the CNS model surfaces. Figure 2 describes the stable geometry of the interaction between the MBBA molecule and zigzag CNT model and reveals the closest separation distance. It is clear from Figure 2 that the MBBA molecule has different conformation compared with Figure 1; especially, the dihedral angle $\left(\mathrm{C}_{1}-\mathrm{N}_{2}-\mathrm{C}_{3}-\mathrm{C}_{4}\right)$ that exhibits $11^{\circ}$ and curvature shape around the CNT molecule. The values of frontier orbital energies (see Table 1) show a difference between the assembly of MBBACNT model and its components that indicate towards the interaction between the MBBA and CNT molecules.

We noted that the interaction was strengthened by the $\pi, \pi$-stacking [17] between the hexagonal rings in the MBBA molecule and those of the zigzag CNT surface that was confirmed by the change in the values of the formal charge of carbon atoms in the aromatic rings (see Table 2). This explains the experimental observations that the ringtype molecule was dominated by $\pi, \pi$-stacking with the zigzag CNT surface $[18,19]$.

We believe that the difference in electronic density and energy levels in both the MBBA 
TABLE 1: QUANTUM PARAMETERS AND ENERGY OF HOMO AND LUMO ORBITALS, DIPOLE MOMENT OF LIQUID CRYSTAL-CARBON NONSOLIDS, AND THEIR COMPONENTS ESTIMATED FROM THE PARAMETERIZED MODEL NUMBER 3 LEVEL.

\begin{tabular}{|c|c|c|c|c|c|c|}
\hline Molecule & $\begin{array}{c}\text { Total energy } \\
(\mathrm{kJ} / \mathrm{mol})\end{array}$ & $\begin{array}{c}\text { Binding energy } \\
(\mathrm{kJ} / \mathrm{mol})\end{array}$ & $\begin{array}{c}\text { Dipole } \\
\text { Moment }(\mathrm{D})\end{array}$ & $\begin{array}{c}\text { HOMO } \\
(\mathrm{eV})\end{array}$ & $\begin{array}{c}\text { LUMO } \\
(\mathrm{eV})\end{array}$ & $\begin{array}{c}\text { Energy Gap } \\
(\mathrm{eV})\end{array}$ \\
\hline MBBA & -280668.2 & - & 2.32 & -8.6082 & -0.6159 & 7.9923 \\
\hline zigzag CNT & -2311004.1 & - & 0.94 & -5.4718 & -4.4875 & 0.9910 \\
\hline Armchair CNT & -2500600.6 & - & 0.00 & -6.7817 & -3.4185 & 3.3632 \\
\hline Graphite sheet & -2317382.8 & - & 2.98 & -5.9915 & -3.7013 & 2.2902 \\
\hline MBBA-zigzag CNT & -2591672.7 & -0.4 & 7.16 & -5.4568 & -4.4747 & 0.9821 \\
\hline MBBA-armchair CNT & -2781264.8 & 4.0 & 1.92 & -6.7827 & -3.4231 & 3.3596 \\
\hline${ }^{1}$ MBBA- Graphite sheet (A) & -2598049.2 & 1.8 & 5.76 & -6.0000 & -3.7106 & 2.2894 \\
\hline${ }^{2}$ MBBA- Graphite sheet (B) & -2598044.2 & 6.8 & 3.32 & -6.0013 & -3.7190 & 2.2823 \\
\hline
\end{tabular}

${ }^{1}$ direction $\mathrm{A} ;{ }^{2}$ direction $\mathrm{B} ;{ }^{\mathrm{a}}$ energy gap =LUMO-HOMO. MBBA (4-methoxybenzylidene-4'-n-butylaniline), CNT (carbon nanotube)

TABLE 2: ELECTRONIC CHARGE DISTRIBUTION IN A MBBA-ZIGZAG CARBON NANOTUBE MOLECULAR SYSTEM AND A MOLECULE OF MBBA USING PARAMETERIZED MODEL NUMBER 3 METHOD.

\begin{tabular}{|c|c|c|}
\hline The atoms & $\begin{array}{c}\text { Mulliken charge } \\
\text { (e/atom), MBBA-CNT }\end{array}$ & $\begin{array}{c}\text { Mulliken charge } \\
\text { (e/atom), MBBA }\end{array}$ \\
\hline $\mathrm{N}$ & -0.059 & -0.061 \\
\hline $\mathrm{O}$ & -0.185 & -0.185 \\
\hline $\mathrm{C}_{\mathrm{a}}$ & +0.102 & +0.104 \\
\hline $\mathrm{C}_{\mathrm{b}}$ & -0.155 & -0.194 \\
\hline $\mathrm{C}_{\mathrm{c}}$ & -0.091 & -0.109 \\
\hline $\mathrm{C}_{\mathrm{d}}$ & -0.072 & -0.065 \\
\hline $\mathrm{C}_{\mathrm{e}}$ & -0.063 & -0.054 \\
\hline $\mathrm{C}_{6}$ & -0.023 & -0.043 \\
\hline $\mathrm{C}_{5}$ & -0.113 & -0.115 \\
\hline $\mathrm{C}_{4}$ & -0.126 & -0.061 \\
\hline $\mathrm{C}_{3}$ & -0.062 & -0.063 \\
\hline $\mathrm{C}_{1}$ & -0.032 & -0.033 \\
\hline
\end{tabular}

${ }^{2} \mathrm{MBBA}(4-$-methoxybenzylidene-4'-n-butylaniline), CNT (zigzag carbon nanotube

and zigzag CNT molecules could be prepared under optimum conditions for non-covalent interactions. Consequently, the separation distances between the atoms of MBBA molecules and carbon atoms in CNT were within the typical van der Waals interaction distance [20], as shown in Figure 2.

Second, we described the interaction model between the MBBA molecule and armchair CNT surface. Figure 3 shows the stable geometry of the interaction between the MBBA molecule and armchair CNT model with the closest separation distance. It also clearly highlights the different conformations of the MBBA molecule compared with Figure 1 ; especially the dihedral angle $\left(\mathrm{C}_{1}-\mathrm{N}_{2}-\mathrm{C}_{3}-\mathrm{C}_{4}\right)$ with a value of $13^{\circ}$ and the curvature shape around the CNT molecule.
Thirdly, we described the interaction between the MBBA molecule and surface of graphite sheet models for two directions A and B (see Scheme 1). Figure 4 shows the stable geometry of the interaction between the MBBA molecule and graphite sheet model (direction A) and predicts the closest separation distance.
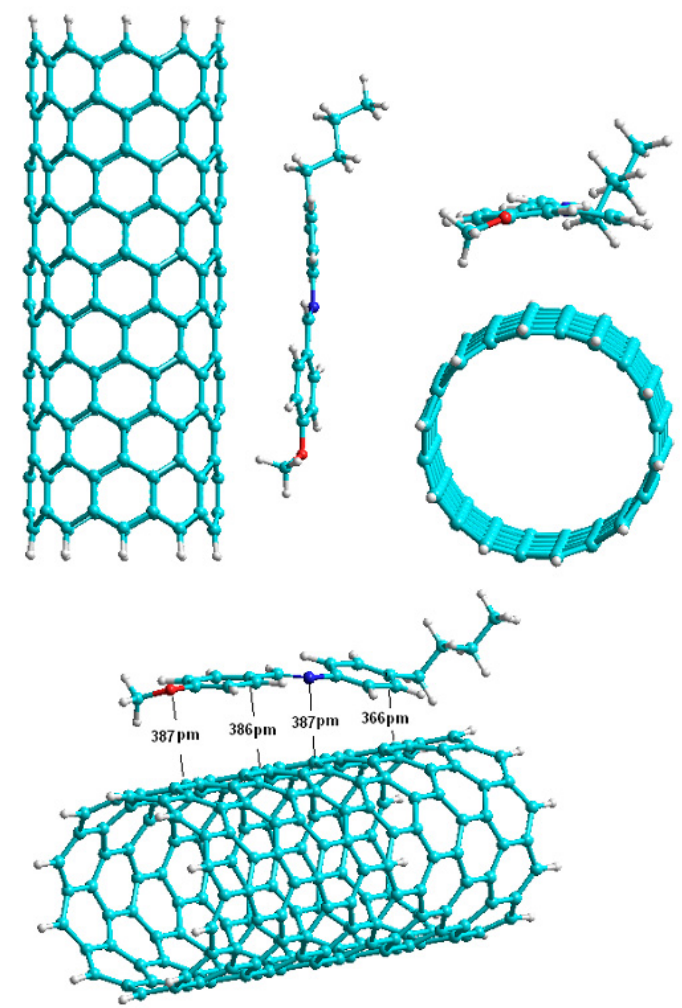

Fig.2. Side and top views of the MBBA molecule that assemble around the zigzag carbon nanotube surface. The distance is in $\mathrm{pm}$ units between the atoms of MBBA and nearest atoms of CNT molecule. 
It also indicates the different conformation of MBBA molecule compared with Figure 1; especially, the dihedral angle $\left(\mathrm{C}_{1}-\mathrm{N}_{2}-\mathrm{C}_{3}-\mathrm{C}_{4}\right)$ with a value of $2^{\circ}$. The curvature shape has occurred to graphite sheet surface.

Lastly, we described the interaction between the MBBA molecule and surface graphite sheet model (directions B) (see Scheme 1). Figure 5 shows the stable geometry of the interaction between the MBBA molecule and graphite sheet molecule with the closest separation distance. Figure 5 confirms the different conformation of the MBBA molecule compared with Figure 1; especially, the dihedral angle $\left(\mathrm{C}_{1}-\mathrm{N}_{2}-\mathrm{C}_{3}-\mathrm{C}_{4}\right)$ with a value of $9^{\circ}$. In addition, the curvature shape has occurred to graphite sheet surface.

Figures 2-5 show the position of MBBA molecule with alternating dihedral angles away from the planarity that is preferred to be located near the CNS surface model.
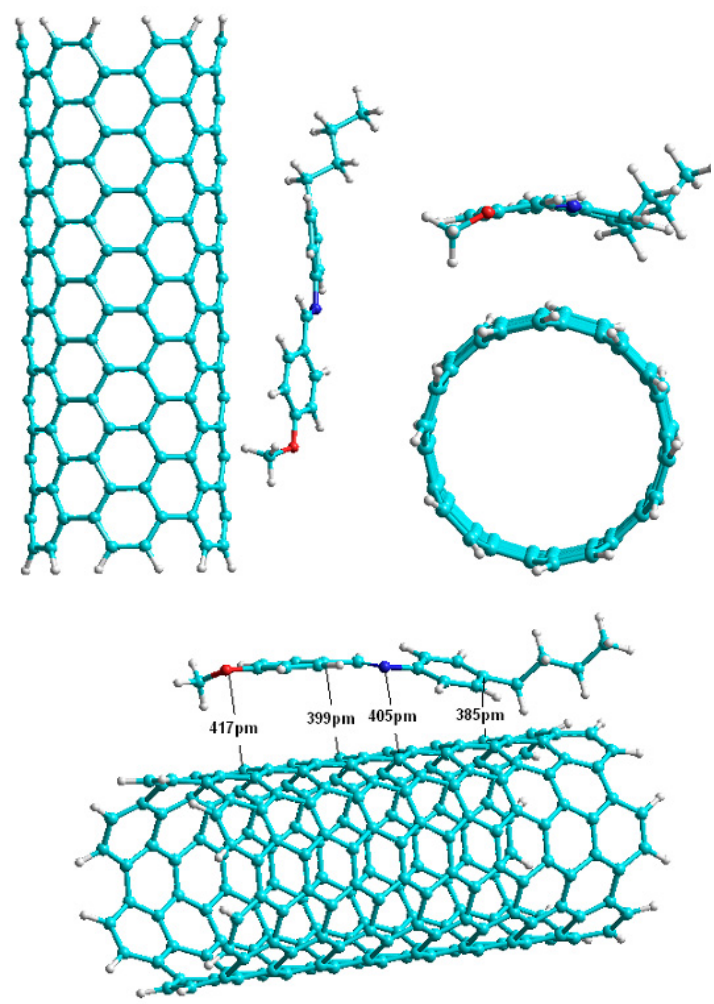

Fig.3. Side and top views of the MBBA molecule that assemble around the armchair carbon nanotube (CNT) surface. The distance is in pm units between the atoms of MBBA molecule and nearest atoms of the CNT molecule.

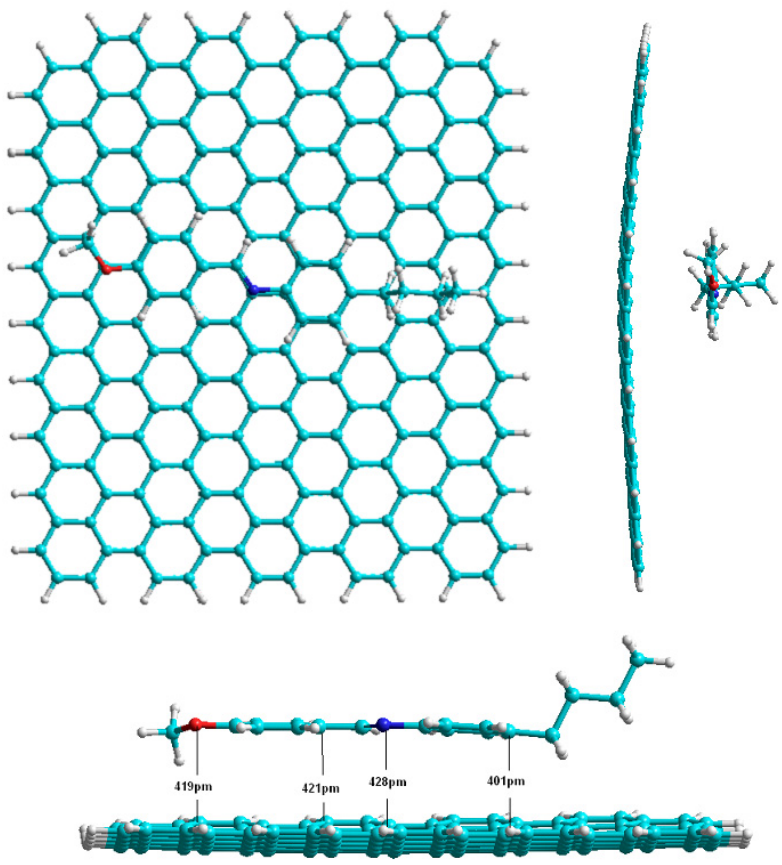

Fig.4. Side and top views of the MBBA molecule that assemble around the graphite sheet surface in direction $\mathrm{A}$. The distance is in pm units between the atoms of MBBA molecule and the nearest atoms of the graphite sheet molecule.

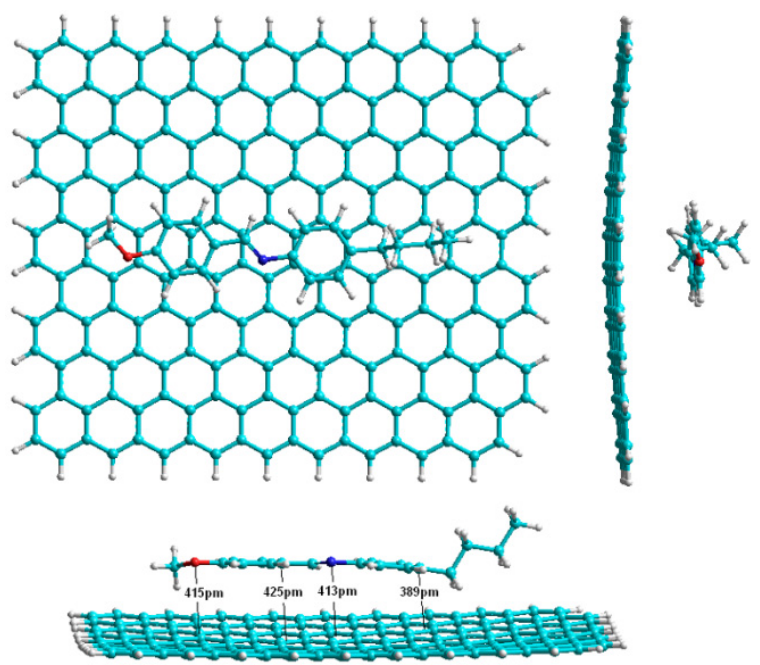

Fig.5. Side and top views of the MBBA molecule that assemble around the graphite sheet surface in direction $\mathrm{B}$. The distance is in pm units between atoms of the MBBA molecule and nearest atoms of the graphite sheet molecule.

The figures also reveal that the functionalized rings of MBBA molecule play an important role in the process of interaction $(\pi, \pi$ stacking) with enriched electronic density on the surface of CNS.

Furthermore, the binding energy (see Table 1) states that the zigzag system models (see Figures 2,4) could be given the proper 
geometrical conformation for $\pi, \pi$-stacking interactions. In addition, the variation in the values of HOMO-LUMO gap (see Table 1) are due to the enhanced electronic properties and electron delocalization caused by the interaction effects between the MBBA molecule and the CNS surface model.

\subsection{ELECTRONIC DENSITY DISTRIBUTION}

The electrostatic potential is a tool that provides insight into the intermolecular association and molecular properties of the molecules. It is also a useful way of understanding the electrostatic complementarities.

Therefore, electronic density distributions of the suggested models have remarkable improvement caused by MBBA molecule that assembles around the CNS surface model. Figure 6 shows the electrostatic potential energy maps obtained due to the assembly of MBBA-CNS models that illustrates the electronic density distributions over the surface area of CNS and MBBA as components.

We believe that the redistribution of electronic density for the MBBA-CNS model assembly compared with the components was dependent on the kind and shape of CNS models and nature of $\pi, \pi$-stacking interactions. The change in electronic density distribution reflected on the values of dipole moments of MBBA-CNS systems assembly (see Table 1). It seemed that although the short CNS model length with symmetrical functionalization at both the edges limited our calculations, this provided the ability to acquire knowledge for the formation of a permanent dipole moment. The induced charge distribution in the CNS models was inevitably asymmetrical along the CNS axis, thereby producing net charges in the CNS and permanent dipole moment. The magnitude of the dipole moment was higher

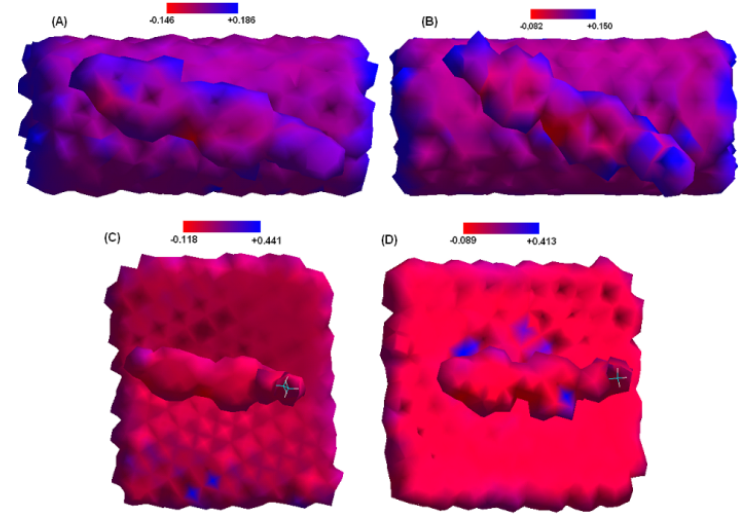

Fig.6. Maps of charge distributions of potential energy of MBBA (4methoxybenzylidene-4'-n-butylaniline)-carbon nanosolid models: A: MBBA-zigzag CNT, B: MBBA-armchair CNT, C: MBBA-graphite sheet (direction A) and D: MBBA-graphite sheet (direction $B$ ) using parameterized model number 3 method.

because of the length of the CNS systems [21]. The presence of a permanent dipole moment in the CNS resulting from the interaction with MBBA molecule can be explained by experimental observations $[18$, 21].

\section{CONCLUSION}

The present work determined stable geometries of MBBA molecule assembled on different CNS surface models by using the semi-empirical molecular quantum calculations within the PM3 method as implemented in the Hyperchem package.

The $\pi, \pi$-stacking between the MBBA molecule and CNS surfaces led to the assembly of LC molecule on the CNS surface, whereas the tail moiety was repelled from the CNT wall. The result of the calculations revealed the LC- CNS models assembly within the typical van der Waals interactions. The lower value of binding energy of the LCzigzag CNT model system assembly makes it an energetically preferable model as compared with others. Further calculations of the permanent dipole moment of the LC-CNS systems assembly could be explained by the redistribution of electronic density. Therefore, the quantum calculations could be useful in the systematic and theoretical analysis of the 
methods applied to the field of material science to understand the physical properties and the nature of interaction with regard to the assembly of organic models.

\section{REFERENCES}

[1] Samue I. Stupp and Liam C. Palmer, Supramolecular Chemistry and Self-Assembly in Organic Materials Design,Chem. Mater., 26 (1), 507-518, 2014.

[2] Cerny J., Hobza P., Non-covalent interactions in biomacromolecules, PhysChemChemPhys, 9, 5291-5303, 2007.

[3] Qureshi A., Kang W. P., Davidson J. L., Gurbuz Y., Review on carbon-derived, solid-state, micro and nano sensors for electrochemical sensing applications, Diamond and Related Materials, 18,1401-1420, 2009.

[4] Jiang J., Lima O.V., Pei Y., Jiang Z., Chen Z., Yu C., Wang J., Zeng X.C., Forsythe E., Tan. L., Self-assembled nanolayers of conjugated silane with $\pi-\pi$ interlocking, ACS Nano, 4, 3773-3780, 2010.

[5] Lagerwall P.F., Scalia G., Carbon nanotubes in liquid crystals. J. Mater. Chem, 18, 2890-2898, 2008.

[6] Rahman M., Lee W., Scientific duo of carbon nanotubes and nematic liquid crystals, J. Phys. D: Appl. Phys., 42, 063001, 1-12, 2009.

[7] Russel J. M., Oh S., La Rue I., Zhou O., Samulski E. T., Alignment of nematic liquid crystals using carbon nanotube films, Thin Solid Films, 509, 53-57, 2006.

[8] Podgornov F., Suvorova A., Lapanik A., Haase W., Electrooptic and dielectric properties of ferroelectric liquid crystal/single walled carbon nanotubes dispersions confined in thin cells. Chem. Phys. Lett., 479, 206-210, 2009.

[9] Baik In-Su., Jeong S. Y., Lee S. H., Park K. A., Jeong S. H., An K.H., Lee Y. H., Electrical-field effect on carbon nanotubes in a twisted nematic liquid crystal cell, Appl. Phys. Lett., 87:263110, 2005.

[10] Park K. A., Lee S. M., Lee S. H., Lee Y. H., Anchoring liquid crystal molecule on singlewalled carbon nanotube, J. Phys. Chem., C, 111,1620-1624, 2007.
[11] Hung F. R., Guzman O., Gettelnger B. T., Abbott N., de Pablo J J., Anisotropic nanoparticles immersed in a nematic liquid crystal: Defect structures and potentials of a mean force, Phys. Rev. E, 74, 01171, 2006.

[12] Quan Li, Liquid Crystals Beyond Displays: Chemistry, Physics, and Applications, WileyBlackwell; 1 edition, 2012.

[13] Andrienko D., Allen M. P., Skacej G., Zumer S., Defect structures and torque on an elongated colloidal particle immersed in a liquid crystal host, Phys. Rev. E, 65, 041702, 2002.

[14] Rashad A. A., Jber N. R., Shihab M. S., Theoretical Approach to Study Assembly Nature of Molecular Modeling System of Carbon Nanotube and a Nematic Liquid Crystal. J. AlNahrain University, 15, 91-97, 2012.

[15] Stewart J. J. P., Optimization of parameters for semiempirical methods I. Method J. Computational Chem., 10, 209-220, 1989.

[16] Csizmadia I. G., Theory and practice of $\mathrm{MO}$ calculations on organic molecules. Elsevier, Amsterdam, 1976.

[17] Tasis D., Tagmatarchis N., Bianco A., Praton M., Chemistry of Carbon Nanotubes. Chem. Rev., 106, 1105-1136, 2006.

[18] Jber N. R., Rashad A. A., Shihab M. S., Effects of carbon nanotubes on the physical properties of a nematic liquid crystal N-(40methoxybenzylidene)-4-butylaniline, J. Mol. Struct., 1043, 28-36, 2013.

[19] Bravo-Sanchez M., Simmons T. J., Vidal M. A., Liquid crystal behavior of single wall carbon nanotubes. Carbon, 48, 3531-3542, 2010.

[20] Atkins, P., de Paula J., Physical Chemistry for the Life Sciences. Oxford, UK, Oxford University Press, 2006.

[21] Baik I-S., Jeon S. Y., Jeong S. J., Lee S. H., An K. H., Jeong S. H., Lee Y. H., Local deformation of liquid crystal director induced by translational motion of carbon nanotubes under in-plane field, J. Appl. Phys., 100074306, 2006. 
منهج نظري لاراسة خصائص التظظيم الذاتي لكريستال السائل الخيطي مع موديلات نانوية كاربونية صلبة

\author{
مهدي صالح شهاب \\ جامعة النهرين، كلية العلوم، قسم الكيمياء، العراق
}

الملخص:

دراسة نظرية للاشكال الهنسية المستقرة لجزيئة الكريستال السائل (4-ميثوكيبنزيليدين-4-ن-بيوتلانيلين) المتجمعةعلى سطح الكربون النانوي الصلب (متل نوع ورقة الجر افيت و أنابيب الكربون النانوي نوع المتعرج، ونوع الكرسي). جربت هذه الحسابات باستخدام حسابات الكم الجزيئية شبه التجريبية ضمن طريقة(PM3) وباستخدام برنامج (Hyperchem). تأثير تفاعل التراص من نوع ( باي-باي) بين جزيء كريستال السائل (4ميثوكيبزيليدين-4-ن-بيوتلانيلين ) وسطح الكربون النانوي الصلب أدى إلى تشكيل نأثرموقعي قصيرة الددى من خلال الحركة التوجيهية لجزيئة الكريستال السائل على سطح الكربون النانوي الصلب نتيجة الى طاقة الربط. وكانت طاقةالربط بين جزيء كريستال السائل وسطح الكربون النانوي الصلب ضمن التأثر النموذجي لقوى فان دير فالز. و أظهرت النتائج أننوع التجمع لجزيئة الكريستال السائل والكربون النانوي الصلب (المتعرج) كان

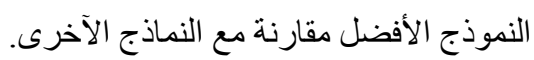

